
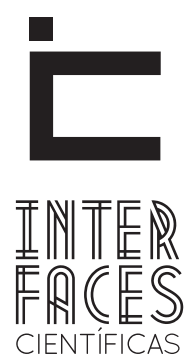

EDUCAÇ̃̃o

\title{
A INSTRUÇÃO SECUNDÁRIA NA PROVÍNCIA DA PARAHYBA DO NORTE: O LYCEU PROVINCIAL ENTRE OS ANOS DE 1836-1846
}

\section{Cristiano Ferronato ${ }^{1}$ \\ Leyla Menezes de Santana ${ }^{3}$ \\ Joelson Silva dos Santos ${ }^{5}$}

RESUMO

\author{
Simone Silveira Amorim² \\ Joseane Gonçalves da Silva ${ }^{4}$
}

O objetivo deste trabalho é apresentar algumas questões iniciais sobre o processo de organização da instrução secundária na província da Parahyba do Norte, entre os anos de 1836 a 1846, tendo como objeto de análise os Estatutos do Lyceu Provincial da Parahyba do Norte publicados em 1846. O corpus documental inclui, além dos citados estatutos, a documentação levantada pelo Grupo de Pesquisa de História da Educação no Nordeste Oitocentista, da Universidade Federal da Paraíba, no Arquivo Público do Estado da Paraíba. A análise do processo de normatização da instrução secundária no XIX, na supracitada Provín- cia, baseou-se nos referenciais teóricos da História Cultural (BURKE, 1992), da História das instituições (MAGALHÂES, 1998/1999) e da cultura escolar (JULIA, 2001). A História das instituições tem tomado fôlego no contexto dos estudos de História da Educação no Brasil, inserindo-se em um processo de renovação na área e constituindo-se como um novo campo temático da historiografia da educação brasileira.

\section{PALAVRAS-CHAVE}

Ensino secundário. Normatização. Liceus. 


\section{ABSTRACT}

The objective of this work is to present some initial questions about the process of organization of secondary education in the province of North Parahyba, between the years 1836-1846, with the object of analysis Statutes Lyceu Provincial Parahyba North published in 1846. The documentary corpus includes, in addition to the cited statutes, the documentation raised by the Research Group for the History of Education in Northeast nineteenth century, Federal University of Paraíba, in the Public Archives of the State of Paraíba. The analysis of the process of normalization of secondary education in the nineteenth, in the Province aforesaid, was based on the theoretical framework of Cultural History (Burke, 1992), the history of institutions (Magalhães, 1998/1999) and school culture (JULIA, 2001) The History of the institutions has taken momentum in the context of studies in History of Education in Brazil, entering into a process of renewal in the area and establishing itself as a new thematic field of historiography of Brazilian education.

\section{KEYWORDS}

Secondary Education. Standardization. High Schools.

\section{INTRODUCÇÃO}

O período compreendido entre anos 1834 a 1846 pode ser considerado como de organização da instrução pública no Brasil. Nesta quase uma década foram tomadas várias medidas no sentido de fazer avançar o processo de organização, consolidação e ordenamento da Instrução Pública e Privada. Entre estas medidas pode-se destacar: o Ato Adicional de 1834, a criação de vários liceus pelo País e a criação Colégio Pedro II. O objeto de nossa discussão neste artigo, o Lyceu Pro-

\section{RESUMEN}

El objetivo de este trabajo es exponer algunas de las preguntas cruciales sobre el proceso de organización de la educación secundaria en la provincia del Norte de Paraíba, entre los años 1836-1846, con el objeto de análisis de los Estatutos do Lyceu Estatal en Paraíba del Norte, publicado en 1846 . El cuerpo documental incluye, además de los citados estatutos, la documentación levantada por el equipo del Grupo de Investigación de Historia de la Educación del noreste del siglo XIX, de la Universidad Federal de Paraíba y el Archivo Público del Estado de Paraíba. Para el análisis del proceso de normalización de la enseñanza secundaria del siglo XIX, en la provincia antes mencionada. Nos hemos besado en la Historia Cultural (Burke, 1992) y la Historia de las Instituciones (Magalhães, 1998/1999) y La cultura de la Escuela (Julia, 2001). La historia de las instituciones ha tomado impulso en el contexto de los estudios de la historia de la educación en Brasil, entrando en un proceso de renovación y estableciendo un nuevo campo temático de la historiografía de la educación brasileña.

\section{PALABRAS CLAVE}

Educación. Secundaría. Normalización. Enseñanza Media.

vincial da Parahyba do Norte, se insere neste período de organização e consolidação do ensino secundário nas Províncias, tendo em vista que foi criado em 1836. No tocante a sua regulamentação oficial, esta se deu em 19 de abril do ano de 1837, com a aprovação de seus estatutos.

A instituição, apesar de ser contemporânea a muitas outras, que foram criadas naqueles anos, tem vá- 
rias características que o diferenciam de seus congêneres. Entre estas podemos destacar questões como, por exemplo, o bom afluxo de recursos financeiros, o número de alunos matriculados e a longevidade da instituição que funcionou como Liceu Provincial durante todo o Período Imperial, tendo a ele sobrevivido e até hoje ser uma importante instituição na formação da juventude paraibana.

Partindo destas considerações pretendemos apresentar neste trabalho algumas questões referentes ao cotidiano do funcionamento do Lyceu, entre os anos de 1836 - ano de criação - e 1846 quando foram pu- blicados o segundo código estatutário da instituição. Para isso, analisamos alguns aspectos que se referem ao processo de consolidação e normatização do ensino secundário a partir do ordenamento da instrução secundária na Província. Para tal análise utilizamos os referenciais teóricos da Nova História que muito têm influenciado os trabalhos dos historiadores da educação na atualidade. Esta pesquisa tem vinculação aos trabalhos desenvolvidos no âmbito do Grupo de Pesquisa em História da Educação no Nordeste Oitocentista (GT-Sergipe ${ }^{1}$ ) e ao Grupo de Pesquisa em História da Educação no Nordeste Oitocentista, sediado na Universidade Federal da Paraíba.

\section{HISTÓRIA DAS INSTITUICÕES ESCOLARES: INFLUÊNCIAS, DESAFIOS E FONTES}

Os historiadores da educação já há algum tempo têm recorrido em suas pesquisas aos referenciais do paradigma da Nova História Cultural que tem contribuído para a ampliação de seu universo de pesquisa e permitido a busca de novas fontes de investigação e de novos objetos de estudo. Este campo ofereceu uma verdadeira revolução da pesquisa, pois ampliou as possibilidades historiográficas fazendo com que esta jamais fosse a mesma.

Jacques Le Goff (2001, p. 28) nos lembra que a Nova História "substitui aquela essencialmente fundamentada nos textos, no documento escrito, por uma história baseada numa multiplicidade de documentos". Este novo fazer historiográfico abriu espaço para o estudo das instituições escolares inserido no campo da História da Educação. O campo da História da Educação foi o que mais absorveu esse novo fazer historiográfico se constituindo num espaço vasto de investigação, podendo o pesquisador enveredar por caminhos os mais diversos que vão desde os aspectos arquitetônicos, estrutural, organizacional, além do ideário pedagógico.

Para Gatti Junior,

\begin{abstract}
a história das instituições educativas investiga o que se passa no interior da escola pela apreensão daqueles elementos que conferem identidade à instituição educacional, ou seja, daquilo que the confere um sentido único no cenário social do qual fez ou ainda faz parte, mesmo que ela tenha se transformado no decorrer dos tempos. (GATTI JÚNIOR, 2002, p. 19).
\end{abstract}

Portanto, esta envolve a tarefa de fazer as descrições sobre o ciclo de vida das instituições como: sua criação, desenvolvimento, crises e extensão, arquitetura, perfil de seus agentes, corpo docente, funcionários, alunos, projetos e propostas pedagógicas, entre outros. Na avaliação de Magalhães:

Compreender e explicar a existência histórica de uma instituição educativa é sem deixar de integrá-la na realidade mais ampla que é o sistema educativo, contextualiza-la, implicando-a no quadro de evolução de uma comunidade e de uma região, é por fim sistematizar

10 Grupo esta sediado no Programa de Pós-Graduação em Educação da Universidade Tiradentes e conta com alunos de professores da graduação e pós-graduação da instituição e professores de outras instituições como UFS e UFPB. 
e (re)escrever-lhe o itinerário de vida na sua multidimensionalidade conferindo um sentido histórico. (MAGALHÃES, 1999, p. 64)

Dentre as formas de estudar a história das instituições escolares se destaca o estudo da cultura escolar, definida por Dominique Julia como:

um conjunto de normas que definem conhecimentos a ensinar e condutas a inculcar, e um conjunto de práticas que permitem a transmissão desses conhecimentos e a incorporação desses comportamentos: normas e práticas coordenadas a finalidades que podem variar segundo as épocas. (JULIA, 2001, p. 10)

Percebe-se nesta formulação que os professores são essenciais e que a cultura escolar também esta além dos muros da escola podendo ser identificada nos modos de pensar e de agir do grupo social que tem a escola como único local de acesso ao conhecimento. Os estudos sobre instituições escolares têm analisado a escola por meio da legislação, da organização, das demandas de escolarização, do pensamento pedagógico.

Portanto, nossa abordagem sobre a cultura escolar se dará a partir da orientação de Juliá (2001, p. 17), ao afirmar que "pode-se tentar reconstituir, indiretamente, as práticas escolares a partir das normas ditadas nos programas oficiais", e das sugestões oferecidas por Magalhães (1998) no que diz respeito às categorias de análise para investigação sobre a história das instituições escolares elegendo alguns elementos para o estudo como o espaço escolar, o currículo, o tempo, os professores e suas práticas, os alunos, a cultura escolar específica desta instituição no período imperial.
Partindo destas premissas acreditamos que a instituição escolar pode tornar-se nova aos olhos atuais na medida em que possamos apresentar aspectos até então ignorados se associarmos a história da educação com a história cultural.

No trabalho com os documentos nossas preocupações tentam abarcar uma preocupação constante com questões de caráter teórico-metodológico que a historiografia atual vem aplicando. Esta preocupação se torna maior quando as fontes têm uma origem oficial, principalmente na quadra histórica com que trabalhamos, ou seja, o Período Imperial brasileiro, onde esse tipo de fonte se torna por vezes a única. É preciso que ela seja trabalhada como "uma" das fontes para análise/interpretação e, sempre que possível, confrontada com outras fontes e sujeitos da história. Faria Filho (1998, p. 124) ressalta particularmente em relação às leis, que podem ser pensadas "como prática ordenadora das relações sociais [...]. Menos óbvio é, por exemplo, estabelecer o repertório discursivo que a legislação põe à disposição e em movimento tendo em vista a conformação do campo pedagógico".

Desta forma, as documentações utilizadas para este trabalho foram os Relatórios de Presidentes de Província entre os anos de 1836 a 1846 e as Leis e Regulamentos da instrução da Paraíba Imperial, produzidos na Província, entre os anos de 1837 a 1889, selecionados nas Collecções das Leis Provinciais (1835-1889)² nas mensagens, relatórios de diretores da instrução pública e correspondências oficiais emitidas no âmbito do poder Legislativo. Acreditamos que através dos relatórios dos presidentes de província e dos diretores da instrução pública podemos avaliar as dificuldades e avanços por que passou a instrução na Província.

2 O material coletado e organizado na Paraíba pelos professores Dr. Antonio Carlos Ferreira Pinheiro e Dra. Cláudia Engler Cury encontra-se publicado na Coleção Documentos de Educação Brasileira pela SBHE/INEP/MEC. 2004 


\section{A INSTRUÇÃO PÚBLICA NO BRASIL NO PRI- MEIRO QUARTEL DO SÉCULO XIX E A CRIAÇÃO DOS LICEUS PROVINCIAIS}

Uma das características que mais nos chama a atenção na História da Educação brasileira durante o período que ora nos atemos, ou seja, o Período Imperial é a lenta evolução do processo educativo que fazia com que esta caminhasse a passos lentos.

O ensino secundário no Brasil, após a expulsão dos jesuítas, ficou reduzido às chamadas Aulas Avulsas ou aulas régias, principalmente às aulas de Latim. Estas eram insuficientes para atender toda a demanda apresentada, além do componente qualitativo e constância no qual estas ficavam a dever. $\mathrm{O}$ ensino secundário nas províncias durante o Período Imperial se caracterizou como um tipo autônomo de educação separado horizontalmente dos demais tipos de ensino como os Liceus e Aulas Avulsas, e sem articulação vertical com o ensino primário. Este funcionava como uma passagem/preparação para os exames de ingresso nos cursos superiores do Império. Devido a esta forma de estruturação, as escolas elementares e secundárias não representavam graus sucessivos e contínuos, mas cursos justapostos, organizações paralelas, que se diferenciavam à base do nível social das respectivas clientelas e da finalidade social a que obedecia a sua formação educativa. Tinham prestígios sociais diversos e visavam a objetivos pedagógicos diferentes distinguindo-se em suas organizações didáticas, na preparação e nas condições de trabalhos de seus professores.

Após a Independência do Brasil, o ensino secundário, que na legislação é sempre mencionado como ensino superior ${ }^{3}$, passou aos poucos a ser

\footnotetext{
30 termo secundário tem sua origem na classe denominada de segunda, de estudos de humanidades e de sentido intermediário e propedêutico aos estudos superiores de retórica. Justifica-se por isso mesmo a designação de estudos menores utilizada para caracterizar esse curso preparatório aos estudos maiores. Essas denominações marcaram o conceito em sua história, das quais a que dava sentido à formação em humanidades foi a maior continuidade.
}

organizado com a criação dos Liceus ${ }^{4}$ Provinciais. Segundo Silva:

Na verdade a expressão ensino secundário chegou ao Brasil com um sentido mais generalizante do que na Europa. Ele não tinha a acepção de um simples nível, "mas a de um tipo de ensino, aquele tipo ministrado em instituições que, entre nós, têm sido chamados de colégios, liceus, institutos, ateneus, e cujo currículo tem concretizado uma conciliação, mais ou menos bem sucedida, entre a tradição pedagógica anterior ao século XIX e as novas condições e necessidades do mundo moderno. (SILVA, 1959, p. 218)

Liceus e Ateneus foram criados em diversas províncias como medida para consolidar o secundário regular, o que indicia uma vez mais as disputas existentes no que se refere à forma escolar do ensino secundário no Império. Alguns destes liceus foram organizados antes mesmo da criação do Colégio Pedro II em 1837. Os Liceus que antecedem ao Imperial Colégio de Collégio Pedro II eram: Lyceu Provincial Pernambuco (1824), Lyceu Sergipense, em sua primeira experiência (1833), Atheneu do Rio Grande do Norte (1835), Lyceu Provincial da Bahia (1836), Lyceu Provincial da Parahyba do Norte e de Santa Catarina (1837).

Estas instituições apresentavam um ensino de caráter propedêutico e procuravam se adequar aos programas do Imperial Colégio de Pedro II, que era

\footnotetext{
$4 \quad 0$ nome Lyceu foi estabelecido no Brasil no ano de 1812, por um projeto de instrução encomendado ao General Francisco de Borja Stocker sendo o primeiro da história da educação brasileira. Era um projeto onde os graus de instrução a serem adaptados estavam de acordo com as tendências em voga na Europa. Há na sua formulação a influência do "Rapport" apresentado por Condorcet à Asssembleia Legislativa francesa em 1792. 0 plano abrangia $1^{\circ}$ - os Pedagogium, escola primária; $2^{\circ}$ - os Institutos, organização correspondente às escolas profissionais médias, para formar agricultores, operários e outros; $3^{\circ}$ - os Liceus, para o ensino médio clássico; $4^{\circ}$ - as Academias, para as chamadas Ciências. 0 terceiro grau formaria os professores dos institutos e seria ministrado ali o ensino de humanidades de acordo com o pensamento liberal europeu.
} 
o modelo para as escolas de ensino secundário. 0 Imperial Colégio de Pedro II foi criado durante a Regência (1831-1840) e essa criação se deveu à iniciativa do ministro Bernardo Pereira de Vasconcellos, para auxiliar na formação de uma elite intelectual, econômica e por que não religiosa brasileira. A instituição foi concebida para ser seguida como padrão para as outras instituições congêneres em todo o Império. O colégio integrava um projeto civilizatório amplo, que era o de preparar os quadros da elite nacional. Sob a forma de um internato masculino, a instituição deveria ser capaz de formar os homens para os altos postos da administração pública. Neste sentido, o colégio representava a primeira iniciativa do Governo Imperial do estabelecimento do ensino secundário público com um plano de estudos integral e estruturado em níveis. No caso das Províncias, alguns governos provinciais já haviam dado início a este processo de organização do ensino secundário para a formação de seus quadros administrativos locais, como o Lyceu Provincial da Parahyba do Norte, criado por Decreto-Lei no 11 de 24 de março 1836. No entanto, tais instituições teriam que adequar seus programas ao recém-criado Collégio.

\section{O LYCEU PROVINCIAL DA PARAHYBA DO NOR- TE E OS ESTATUTOS DE 1846}

O Liceu Provincial da Parahyba do Norte foi criado pela Lei n. 11 de 24 de março de 1836, sendo oficialmente regulamentado em 19 de abril do ano seguinte, com a aprovação de seus estatutos. A lei de criação da instituição foi promulgada pelo presidente em exercício, Manuel Maria Carneiro da Cunha, e diz no seu primeiro artigo:

Art.I - Fica estabelecido nesta cidade um Liceu que será composto dos professores das cadeiras de Latim, Francês, Retórica, Filosofia e primeiro ano de matemática, já criadas na mesma cidade, de dois substitutos, um para estas duas últimas cadeiras e outro para as primeiras, e finalmente, um porteiro. (PINHEIRO;CURY, 2004, p. 92)

No momento de sua criação, a primeira sede da instituição foi no $1^{\circ}$ andar da Assembléia Provincial, depois foi transferido para um salão do Palácio do Governo da Província. Posteriormente, foi transferido para o complexo jesuítico onde permaneceu durante 100 anos, sendo levado em 1938 a um edifício de características modernas situado na Avenida Getúlio Vargas, na hoje cidade de João Pessoa, sua sede até os dias atuais.
Podemos entender a organização da instituição como uma decorrência do Ato Adicional (12 de Agosto de 1834) à Constituição de 1824. Este adendo à carta Imperial foi o instrumento legal mais importante para a educação do período, com implicações que se estenderam até aos nossos dias. A emenda teve como objetivo diminuir os conflitos do Período Regencial dividindo o poder ao criar as Assembleias Provinciais e dar a estas, no artigo $10^{\circ}$ parágrafo $2^{\circ}$, o direito de legislar sobre instrução pública e estabelecimentos próprios a promovê-la, não compreendendo as faculdades de medicina, os cursos jurídicos, academias atualmente existentes e outros quaisquer estabelecimentos de instrução que para o futuro forem criados por lei geral. Este adendo desencadeou uma vasta discussão entre centralização e descentralização no Brasil Imperial, no que se refere à instrução ${ }^{5}$, questões como: "Quem teria o poder de legislar e organizar a instrução pública? Ao governo geral ou às Províncias $^{6}$ ?, estiveram no centro do debate.

\footnotetext{
5 Sobre esta questão conferir: Ferronato (2012).

6 Sobre este tema conferir trabalho de André Paulo Castanha na Revista Brasileira de História da Educação de jan/jun de 2006, n. 11
} 
A partir da criação do Lyceu Provincial da Parahyba do Norte, a instrução secundária vai começar a despontar na Província, uma vez que em nível local a instituição foi no âmbito da instrução pública a primeira tentativa de sistematização dos estudos secundários que estavam na Província, como em todo o Império, fragmentados em aulas avulsas, à semelhança das aulas régias dos tempos coloniais.

0 processo de organização da instituição, assim como de seus congêneres, se insere no momento de aperfeiçoamento do homem e de normatização e ordenamento da instrução pública. A preocupação que existia na mente dos legisladores naquele momento era da construção do Estado e da Nação, por isso a importância da fundação de tais instituições para formar os homens que seriam os dirigentes daquele Estado que estava em construção. A escola naquele momento passou a ter uma espécie de "missão civilizadora", e na Província da Paraíba do Norte não foi diferente.

As vicissitudes por que passaram essas instituições provinciais podem ser interpretadas por um conjunto de variáveis de natureza diversa, inclusive das que poderíamos considerar de caráter estritamente educacional. Uma série de obstáculos teria entravado o desenvolvimento dos liceus, e de todo o ensino secundário público no País, e feito com que apenas uma diminuta clientela a eles afluísse durante todo o período imperial e, na República, até o advento da década de 1930.

No que se refere à sua normatização e consolidação, a década de 1836 a 1846 foi um período de extrema importância para a instituição. Neste processo, as maiores preocupações dos gestores provinciais com relação ao Lyceu eram relativas ao número de alunos, aos gastos com a Instituição, aos métodos e compêndios, à disciplina e aos professores. Este processo de normatização ficou mais claro a partir da aprovação dos Estatutos de Fevereiro 1846, que vieram a substituir aqueles que o regiam desde sua criação, redigidos por Basílio Quaresma Torreão, em 1837. Entendemos que a partir desta importante documentação pudemos ter acesso a alguns importantes aspectos do cotidiano da instituição.

Os Estatutos de 1846 foram aprovados depois de um intenso debate que envolveu o Legislativo e o Executivo, uma vez que na visão de alguns dirigentes provinciais, os que regiam a instituição naquele momento não estavam trazendo a sua prosperidade, como se percebe pelo Relatório do presidente da Província, Agostinho da Silva Neves, de 1844, este diz que:

\begin{abstract}
Este estabelecimento marcha com regularidade, e eu pretendo com mais vagar examinar os methodos, e compêndios pelos quaes ensina, e os estatutos que o regem, para lhes fazer aquellas reformas, que mais azadas forem, para a prosperidade do estabelecimento, e utilidade que deve prestar á Província (PARAHYBA DO NORTE, Relatório, 1844).
\end{abstract}

A leitura e análise dos artigos que compõem os Estatutos de 1846 do Lyceu nos permite conhecer e avaliar o funcionamento da instituição. 0 documento é composto de 99 artigos e vários parágrafos. Indício que reforça o quão importante era a instituição e a dimensão social que a mesma foi recebendo ao longo dos anos. Os Estatutos trouxeram em seu corpo a distribuição dos compêndios, a regulamentação das jubilações, das matrículas, das férias, dos professores, enfim de toda a organização interna do Lyceu Provincial da Parahyba do Norte. O objetivo maior de tal documento era o de ordenar as funções e atribuições no interior da instituição como a do Director, que era indicado pelo presidente da Província.

0 afluxo de alunos nas instituições liceais criadas no Brasil no período imperial sempre foi pequeno para a importância de tais instituições e dentre um dos fatores que levavam a esta diminuição estava o processo de equiparação ${ }^{7}$ obrigatória ao Imperial Co-

7 Numa rápida pesquisa em material que trata da questão do secundário no Brasil, todos fazem menção ao "problema da equiparação e dos exames parcelados", por exemplo, MONTENEGRO, que afirma: "os diretores do Ginásio (Pernambucano) dessa época não costumam falar dos exames parcelados senão com 0 acabrunhamento e a dor de quem se refere 
légio de Pedro II. Esta obrigatoriedade tornava pequena e oscilante a afluência de alunos aos liceus.

No que se refere ao Lyceu Provincial da Parahyba do Norte, a instituição teve uma média de 60 alunos por ano. No entanto, apesar de pequeno e oscilante, este número o colocava em posição diferenciada se compararmos com outros lyceus espalhados pelo País, como no caso do Lyceu Provincial do Piauí, que segundo Reis e Ferro (2006) tinha como maior "dificuldade a falta de interesse dos pais e dos alunos ocasionando uma frequência muito baixa e irregular". São as mesmas autoras que nos fornecem os números das matrículas naquela instituição, que no ano de 1851 teria apenas 51 alunos, o que levou o presidente da Província a afirmar: "Pode-se dizer que o Liceu existia apenas na legislação e que somente se sabia da sua existência quando seus empregados iam receber vencimentos" (apud MOACYR, 1939, p. 254). Num sentido oposto, sobre o Lyceu Provincial da Parahyba do Norte, o que a documentação analisada nos apresenta é que no período de 1838 a 1846, a instituição teve anualmente um acréscimo de matrículas chegando ao ano de $1846 \mathrm{com} 85^{8}$.

Com a promulgação dos Estatutos de 1846, o Liceu Provincial recebeu um grande apoio da administração provincial que veio na forma de um acréscimo de pessoal, com a chegada de sete professores vitalícios, cinco proprietários e dois substitutos, além de um diretor nomeado pelo presidente da Província e de mais recursos financeiros.

Com relação ao aporte financeiro da Província no Lyceu, podemos perceber que esta recebia um grande investimento, tal fato pode ser exemplificado quando analisamos os números de 1842. Naquele ano, a Assembleia Provincial aprovou em seu orçamento um aporte de 6:760,00 para o Lyceu, de um total de 99:003,207 contos para a Província, ou seja, 6,8\% do orçamento provincial se destinava àquela instituição.

a uma grande desgraça" (1943:237).

8 1838: 120;1842: 47; 1843: 66; 1844: 72; 1845: 81; 1846: 85.
Os professores tiveram seus salários melhorados e as matrículas tiveram seus valores orçados em $3 \$ 200$ por ano letivo. A aprovação dos Estatutos, na visão de seu diretor, dava ao Lyceu uma posição de "mais estabilidade e firmeza".

No Ato de sua criação, o Lyceu teve como matriz curricular inicial as seguintes disciplinas: Latim, Francês, Retórica, Filosofia e primeiro ano de matemática. Tais disciplinas, como em todos os outros estabelecimentos de ensino secundário do período, tinham como ênfase a formação do homem civilizado à moda europeia. A esta matriz foram adicionadas pela Lei de 1839, a cadeira de Inglês, em 1841 a de Gramática da Língua Nacional e de Comércio. Esta última tinha sido em 1838, motivo de análise do então presidente da Província Joaquim Teixeira Peixoto de Albuquerque, preocupado com o desenvolvimento do comércio da Província,

Seria igualmente interessante que Assembléia se lembrasse de criar h ua Aula de Comércio, em qual se ensinasse a escripturação por partidas dobradas, reducção de pesos, e medidas, Câmbios, Seguros, avarias \& A criação desta cadeira acarretaria com sigo não poucos benefícios, por que devendo esta Província, pela sua localidade, e excelente Porto, ser bastante Comercial, lucraria não pouco, que se applicassem aos estudos mercantis, quando não a todos, pelo menos aos mais necessários, aqueles a que essa vida se quisessem dedicar. 0 verdadeiro Negociante é $h \sim u$ hom e instruído; pelo menos no quem é relativo ao seo emprego, e occupação: elle deve conhecer a Legislação a que está sujeito, pelo gênero de vida que adoptou, as penas em que incorre, pela infração de qualquer Contracto; o modo prático porque deve proceder à escripturação dos seos Livros, e tudo depende de h u estudo bem coordinado. [...] Esta aula se acha em todos os Paizes civilisados, e entre nós já tem logar em algumas Províncias do Império; (PARAHYBA DO NORTE. FALLA, 1838)

Os Estatutos trazem também os compêndios a serem utilizados que são articulados às cadeiras. Com relação aos compêndios utilizados, podemos identificar no artigo 39 do capítulo 14 os seguintes: 1. Gramatica Latina: do Padre Antonio Pereira; Cornélio, 
Vida dos Imperadores, Fábulas de Phedro; Salustio, Vergílio; Arte Poética, de Horacio. 2. Gramatica Francesa, o de Savene; Aventuras, de Telêmaco; Teatro, de Voltaire. 3. Rethorica; do Padre Marinho, Poética, de José Pedro da Fonseca, Geografia, de Urculo; Chorographia, do Padre Miguel; História, principalmente do Brasil, de Bellegarde. 4. Philosophia, de Geruzer e 5. Arithmética, de Bezourt; Álgebra, de Lacroix; Geometria e Trigonometria, de Legrand. Pode-se perceber nesta lista a força da formação humanista, a recomendação de clássicos, o espaço de padres e da língua francesa na produção de livros como também o tributo à vida imperial.

A partir da aprovação dos Estatutos iniciou-se também a normatização do pessoal do Lyceu que foi tendo suas funções e atribuições definidas. Desta forma, ficou definido que o pessoal da instituição seria composto por sete professores, sendo que cinco eram proprietários e dois substitutos, além de um Bedel e da Congregação. Um elo importante neste processo eram os professores que de certa forma eram responsáveis também por fazer chegar estas práticas ordenadoras a toda à sociedade, cumprindo assim uma espécie de missão civilizadora.

O corpo docente do Liceu era basicamente formado por intelectuais conhecidos da Província e abarcava em seu meio um grande número de padres, já que o ensino da Moral se fazia muito importante. Estes professores se tornavam vitalícios a partir de cinco anos de trabalho e a sua contratação se dava depois de prestarem exame prévio de habilitação. No que se refere ao seu recrutamento, esta era uma preocupação constante, visto que o salário era por vezes muito baixo em uma Província pobre como a Paraíba.

O Estado provincial exercia um controle com relação à conduta pessoal da vida de todos os professores, tanto do primário quanto do secundário. Exigia-se que todos deveriam ser homens de boa conduta, neste item os professores do ensino secundário, ou mais precisamente do Lyceu Provincial, eram sempre vistos como mais preparados e cumpridores dos seus deveres que os de primeiras letras, em virtude de sua origem social. Os professores do Lyceu eram um grupo de homens intelectualmente preparados e de grande reconhecimento pela sociedade provincial paraibana, suas origens podem ser buscadas em setores como a religião, o direito, a literatura e a imprensa.

Em relação aos exames no Lyceu Provincial, aqueles eram organizados nas sabatinas, e disciplinas como Rethorica e Philosophia exigem a construção de dissertações e de teses a cada três meses. Para passar na disciplina era preciso saber, segundo os Estatutos, e o aluno que chegasse a ter dez faltas sem uma justificação era reprovado no ano escolar, participando dos exames apenas se merecesse a confiança da direção da instituição.

Foi a partir da sua criação que tivemos lançadas as bases da organização do ensino público secundário na Província, sem mencionar o fato de que como os seus congêneres regionais foi em alguns momentos a única opção de ensino secundário que os jovens da Província tinham acesso. 
A partir da análise dos Estatutos de 1846 da instituição, pudemos entender como a cultura escolar foi sendo organizada e se consolidando a partir dos atos de normatização do poder público. Acreditamos que a reconstituição da história desta importante instituição de ensino brasileira possa trazer alguma contribuição para o entendimento da história da educação local e nacional.

\section{REFERÊNCIAS}

BURKE, Peter. A escrita da História: novas perspectivas. São Paulo: Unesp, 1992a.

CASTANHA, André Paulo. O Ato Adicional de 1834 na História da educação brasileira. In: Revista Brasileira de História da Educação. Campinas, SP: SBHE/Autores Associados, 2006, $11^{\circ}$ número.

FARIA FILHO, Luciano Mendes de. A legislação escolar como fonte para a história da educação: uma tentativa de interpretação. In: VIDAL, D. G.; GONDRA, J. G.; FILHO, L. M. F.; DUARTE, R. H. (Org.). Educação, Modernidade e Civilização. Belo Horizonte: Autêntica, 1998. p. 89-125.

FERRONATO, Cristiano de Jesus. Das aulas avulsas ao Lyceu Provincial: as primeiras configurações da instrução secundária na Província da Parahyba do Norte (1836-1884). UFPB: João Pessoa, 2012. Tese (Programa de Pós-Graduação em Educação) - Centro de Educação, Universidade Federal da Paraíba, 2012.

GATTI JUNIOR, Décio. A história das instituições educacionais: inovações paradigmáticas e temáticas. In: Araújo, José Carlos Souza; GATTI JUNIOR, Décio (Org). Novos temas em história da educação brasileira: instituições escolares e educação na imprensa. Campinas: Autores Associados; Uberlândia/MG: EDUFU, 2002. p. 3-24.

JULIA, Dominique. “A cultura escolar como objeto histórico”. Revista Brasileira de História da Educação. Campinas, SP: SBHE/Editora Autores Associados, 2001, 1ºúmero.

LE GOFF, Jacques. A história nova. São Paulo: Martins Fontes, 2001.

MAGALHÃES, Justino. Contributo para a história das instituições educativas- entre a memória e o arquivo. In: FERNANDES, Rogério; MAGALHÃES (ORG). Para a história do ensino liceal em Portugal. Braga: Universidade do Minho, 1999.

MAGALHÃES, Justino. Um apontamento metodológico sobre a história das instituições educativas. In: Práticas educativas, culturas escolares, profissão docente. II Congresso Luso-Brasileiro de História da Educação, 1998.

MONTENEGRO, O. Memórias do Gimnásio Pernanbucano, Recife: [s.n], 1943 
PINHEIRO, Antonio Carlos Ferreira; CURY, Cláudia. Leis e Regulamentos da instrução da Paraíba no Período Imperial. Brasília, DF:MEC/INEP, 2004. CD/ROM (Coleção documentos da educação brasileira).

REIS, Amanda de Cássia Campos; FERRO, Maria do Amparo Borges. Liceu Provincial do Piauí. Primeira etapa de uma história em construção. In: Congresso Luso-Brasileiro de História da Educação, 6., 2006, Uberlândia. Anais... Uberlândia: UFU, 2006.

SILVA, G.B. Introdução à critica do ensino secundário. Rio de Janeiro: Cades/MEC, 1959.

\section{FONTES}

FALLA DO PRESIDENTE DA PROVINCIA DA PARAHYBA DO NORTE- na Assembléia Legislativa Provincial no dia 24 de junho de 1838.

RELATÓRIO DO PRESIDENTE DA PROVÍNCIA DA PARAHYBA DO NORTE - na Assembléia Legislativa Provincial no dia 3 de maio de 1844. Pernambuco, Typ. de M.F. de Faria, 1844. Pós-graduação em Educação. Doutor em Educação pela Universidade Federal da Paraíba (UFPB)/ Coordenador do Grupo de Pesquisa História da Educação no Nordeste Oitocentista (GHENO/GT-SE), Aracaju, Sergipe, Brasil, E-mail: cristiano_jesus@unit.br.

2 Professora do PPG I da Universidade Tiradentes/Unit, no Programa de Pós-graduação em Educação. Doutora em Educação pela Universidade Federal de Sergipe (UFS)/ Grupo de Pesquisa História da Educação no Nordeste Oitocentista (GHENO/GT-SE), Aracaju, Sergipe, Brasil Email: Simone_silveira@unit.br.

3 Mestranda em Educação pela Universidade Tiradentes/Unit /Grupo de Pesquisa História da Educação no Nordeste Oitocentista (GHENO/GT-SE)/ Bolsista Procapes 2 /Unit, Aracaju, Sergipe, Brasil, E-mail: leyla. menezes@gmail.com.

4 Graduanda do curso de História da Universidade Tiradentes. Membro do Grupo de Pesquisa História da Educação no Nordeste Oitocentista (GHENO/GT-SE), Aracaju, Sergipe, Brasil, E-mail: josy_historiadora@ live.com.

5 Graduando do curso de História da Universidade Tiradentes. Membro do Grupo de Pesquisa História da Educação no Nordeste Oitocentista (GHENO/GT-SE), Aracaju, Sergipe, Brasil, E-mail: joelson_historia@ live.com. 